\title{
Project Managers: Born Or Made?
}

Leslie Lorenz, (E-mail: ljlorenz@ tech.purdue.edu), Purdue University

Kevin Dittman, (E-mail: kcdittman@tech.purdue.edu), Purdue University

\begin{abstract}
As the world of project management expands, good project managers are becoming a valuable asset to have in an organization. These project managers must not only have an outstanding grasp of the basic project management principles, but the overall leadership skills to be successful. This paper will discuss the skills a project manager must have to be proficient and whether these skills are innate or can be imbibed over time. This paper will also examine personality traits of the exceptional project manager and whether personality assessments are able to predict the possibility of a career in project management. With this information, organizations can understand the value what good project managers can bring to their organization and why it is essential to find project managers that have the capabilities of leading projects successfully.
\end{abstract}

\section{Introduction}

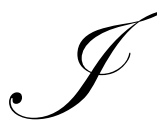

their team to discover solutions against impossible odds to save the astronauts' lives. In this situation, Krantz exhibits the traits of a "superstar" project manager by rallying the team towards a common goal. They could have easily given up, or made an error in judgment, however they relied on their instinct as well as their training to get Apollo 13 home. Krantz was a true leader and he made everyone believe that "Failure was not an option."

It can be seen from the movie Apollo 13 that when put in a stressful situation, we tend to revert back to what we know, our core personality and instincts. This can be true for any situation, from space to the office. In the office there are many stressful situations that need to be handled with finesse. As project managers it is key that when this occurs, we are going to be making the correct decisions based on what we know and our intuition.

As organizations are becoming more "project" based, the current number of IT project management positions is creating demand for great project managers. It is important for these organizations to place individuals in the project manager role that have the skills to be successful. This paper will examine this concept as well as look at the necessary skills actually needed by an IT project manager to succeed. There is a large debate occurring in the project management world as to whether these skills (technical and behavioral) are inherent or whether they can be taught.

The paper will also look at what type of personality would be the best to be placed in the project management role and the different tools we can use to determine what these personality types are. In conjunction with that, we will examine whether this ideal personality can be taught in a classroom, be it a college level project management course or an organizational training program. Choosing an individual that has the skills to be a good project manager is important to the ultimate success of an organization. It is necessary to understand how to assess these individuals and to know what still can be done to produce a project manager with the right skills to make each project they undertake successful. 


\section{Skills Of A Project Manager}

The basis of good project management is having the knowledge and skills necessary to perform the job. A project manager is generally defined as the person responsible for working with the project sponsor, the project team, and the other people involved in a project to meet project goals (Schwalbe, 2004). Being am IT project manager requires knowledge in the core skills such as time management, risk management, scope management, cost budgeting, and a basic knowledge of IT systems.

A project manager must have skills in addition to the basics of project management to succeed. According to David Foote "It requires all these soft skills that have to do with getting things that you want (and) adjudicating issues between people, managers, egos and agendas. It's how to get a job done without annoying people" (Melymuka, 2000). These soft skills can include basic leadership and team building abilities that are needed for the team to complete the designated project. Basic business skills are also needed for a project manager to be successful in the IT world. These can include the ability to communicate into measurable results, utilize financial skills to keep the project cost effective, and identify and predict trends in the project.

Another important aspect of project management is the ability to communicate effectively. It is essential for project managers to have the capacity to listen and understand the people on their project team as well as the customers of their project. By doing so, expectations and feedback can be easily passed on to the team and it will be easier to solve problems and complete tasks within the project. A project manager will also need to be able to step outside the box and see things from a different perspective. Dennis Johnson, an Assistant vice President at USAA states "A project manager needs the ability to question without alienating - to listen and watch people's body language and really see what's happening" (Melymuka, 2000). This will allow the project manager to better communicate with the team and the organization.

Relationship management is a skill that is important to have while managing projects. The project manager should be capable of working with all levels within the organization. This means they should be able to communicate information to different levels of people and understand and have the ability to establish relationships with them. Relationship management can also include identifying the unique characteristics and abilities of each individual on the team and determine the most effective way to utilize them throughout the project. A project manager will also need to know how to mobilize and coach the people on their team. Another aspect of relationship management is establishing trust within the project team. "The project manager and the team must develop a level of trust and comfort with each other in single-minded pursuit of project goals" (Kharbanda, 2003). It comes down to the idea that project managers must be able to build and sustain relationships within their project team and in all levels of their organization.

There are many skills a project manager may have that are argued to be ingrained in the human spirit, the largest of these being the ability to influence others. Linda Pittinger, CEO of People3, states "It's hard to find people who can influence others and create win-win situations (Melymuka, 2000). The project manager needs to have the ability to sell the value of the project to other people within the organization and must be able to persuade and influence team members to get their job done well and on time. A project manager also must have the confidence, credibility, and commitment to overcome the obstacles when faced with the task of running an IT project. Without these, a project manager will be more likely to fail.

There are also many skills a project manager may have that can be either learned or innate, like the ability to make decisions. It has been said that the best decision makers are the most experienced decision makers. "As a manager and leader, every step you take required decision making skills. What makes it more challenging is the pressure to make the right decision is often very high" (Canterucci, 2003). Making the right decision often involves basing that decision on past experience and gut instinct. No project manager will have the experience if they are new to the field of project management but they will have the ability to judge based on gut instinct and other projects within the organization. 


\section{Leadership}

Most CIO's and upper level management believe that the quality of their organization's leadership is high. When attempting to understand the qualities of a good project manager, general leadership can be examined. These "soft skill" traits of a project manager have their foundation in good leadership skills. Artner (2001) believes that one must have three skills to be a good leader:

1. Identifying the major challenges that face the organization

2. Motivating a team to meet those challenges

3. Keeping that team focused on the major challenges

These are just the tip of the iceberg. A leader must have good communication skills as well as the ability to inspire others. In a study made by CIO Insight (2003), leadership skills and personal characteristics were examined in terms of which would lead to effective leadership.

\begin{tabular}{|l|c|c|c|}
\hline $\begin{array}{l}\text { Of the following skills, which three do you feel are } \\
\text { most critical for IT executives to be effective } \\
\text { leaders? Which do you consider to be your } \\
\text { strongest? Which do you most need to improve? }\end{array}$ & $\begin{array}{c}\text { Most } \\
\text { Critical }\end{array}$ & Strongest & $\begin{array}{c}\text { Needs } \\
\text { Improvement }\end{array}$ \\
\hline Communication & $64.5 \%$ & $46.6 \%$ & $31.4 \%$ \\
\hline Relationship Building & $52.7 \%$ & $44.1 \%$ & $30.7 \%$ \\
\hline Strategy creation & $41.7 \%$ & $47.9 \%$ & $23.9 \%$ \\
\hline Recruiting competent people & $36.8 \%$ & $29.5 \%$ & $21.0 \%$ \\
\hline Coaching and mentoring & $36.0 \%$ & $43.3 \%$ & $27.7 \%$ \\
\hline Change management & $24.7 \%$ & $24.3 \%$ & $30.4 \%$ \\
\hline Project management & $24.5 \%$ & $36.9 \%$ & $22.1 \%$ \\
\hline Negotiating & $15.7 \%$ & $21.2 \%$ & $50.6 \%$ \\
\hline
\end{tabular}

\begin{tabular}{|l|c|c|c|}
\hline $\begin{array}{l}\text { Of the following personal characteristics, which } \\
\text { three do you feel are most critical for IT executives } \\
\text { to be effective leaders? Which do you consider to } \\
\text { be your strongest? Which do you most need to } \\
\text { improve? }\end{array}$ & $\begin{array}{c}\text { Most } \\
\text { Critical }\end{array}$ & Strongest & $\begin{array}{c}\text { Needs } \\
\text { Improvement }\end{array}$ \\
\hline Ability to inspire others & $64.2 \%$ & $46.5 \%$ & $37.5 \%$ \\
\hline Vision of the future & $63.5 \%$ & $51.7 \%$ & $29.0 \%$ \\
\hline Integrity & $51.9 \%$ & $55.6 \%$ & $4.7 \%$ \\
\hline Creativity and innovation & $31.6 \%$ & $42.5 \%$ & $32.2 \%$ \\
\hline Willingness to take risks & $26.9 \%$ & $26.3 \%$ & $41.5 \%$ \\
\hline Intelligence & $21.2 \%$ & $35.9 \%$ & $9.0 \%$ \\
\hline Self-Confidence & $19.4 \%$ & $21.6 \%$ & $40.6 \%$ \\
\hline Maturity & $12.7 \%$ & $14.7 \%$ & $19.2 \%$ \\
\hline
\end{tabular}

Adapted from CIO survey on effective leadership

\section{The Project Manager Personalities}

A person's character and personality traits play a key role as to whether they will make an effective leader and project manager. Many IT university programs and organizations believe that this "personality" can be taught in the classroom. It was demonstrated earlier that the greatest responsibility of a project manager is managing people 
successfully. However, can we really teach someone how to interact with people based upon books? Within an IT project management program, can we really prepare our students for the trials of dealing with people while managing a project?

If this is something that we choose to teach in our classrooms, it would be an ultimate goal for us as educators to attempt to identify those that are ideal for project management and encourage them to pursue it as a career. This can be done by using personality tests, such as the Myers-Briggs Type Indicator, to assess whether someone will make a good project manager. By taking those types of assessments, an individual can analyze their personality and connect their personality type with career and jobs.

The Myers-Briggs Type Indicator (MBTI) assessment is incredibly popular for doing just this. "The MBTI descriptions of personality did what no other personality instrument has done before, be able to give most people some insight into themselves and others" (Viawest, 2003). After taking the MBTI, an individual will by given four letters that will match with their personality type: Extrovert v. Introvert, Sensing v. Intuitive, Thinking v. Feeling, and Judging v. Perceiving.

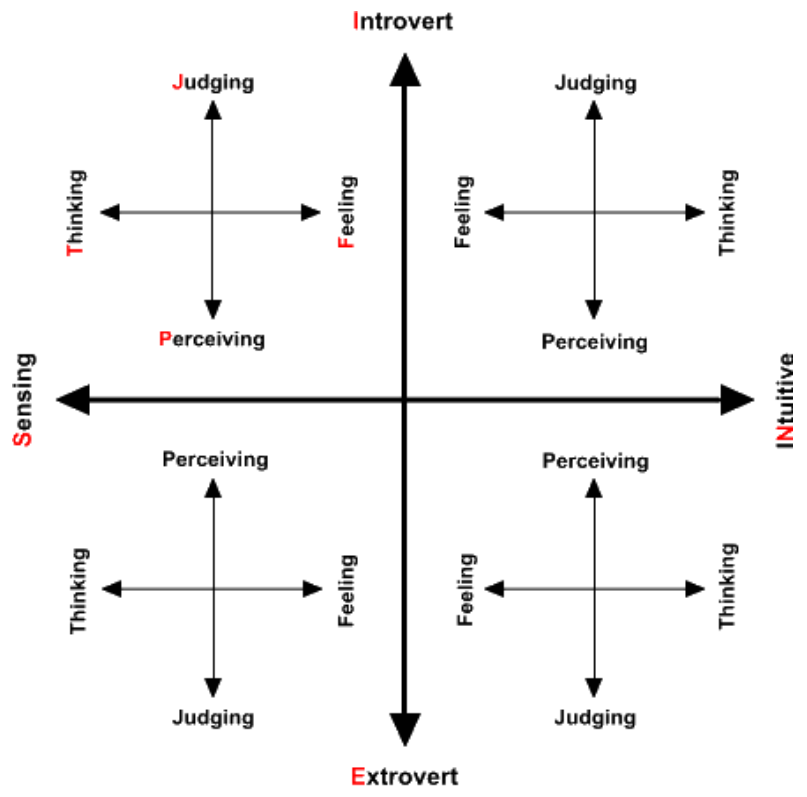

Note: The red capitals in the main and first quadrants refer to the RMW 2/10/a? Myers-Briggs Type Indicators (MBTI)

Once we know this information, we can consult the research database of MBTI that connects personality types with careers. By doing this, it can be shown that leaders most fall into the ENTJ category (extrovert, intuitive, thinking, and judging). "ENTJ's are especially well-suited to be leaders and organization builders. They have the ability to clearly identify problems and innovative solutions for the short and long terms well-being of an organization"(BSM Consulting, 2000). Possible career paths are computer consultants, business administrators, personnel manager, management trainer, corporate team trainer, financial planner, and network integration to name a few. Taking a look at the previous careers, a project manager needs to play all these roles to be successful.

A project manager could also fall into the category of ESTJ. "They are good at a lot of different things, because they put forth a tremendous amount of effort towards doing things the right way. They will be happiest in 
leadership positions, however, because they have a natural drive to be in charge. They are best suited for jobs which require creating order and structure" (BSM Consulting, 2000). Possible career paths for someone who is an ESTJ include business administrator, manager, budget analyst, project manager, computer systems analyst, and teacher.

The Keirsey Temperament Sorter has often been compared to the Myers-Briggs Type indicator. "The Temperament Sorter was created to help people gain new understanding of their traits, motivations, and behaviors" (AdvisorTeam, 2003). The temperament sorter is an assessment to analyze one specific aspect of one's personality: temperament. "Temperament is a set of inclinations that each of us is born with, it's a predisposition to certain attitudes and actions" (AdvisorTeam, 2003).

The four temperaments that people will fall into are artisans, guardians, idealists, and rationals. AdvisorTeam designates each temperament as the following:

- $\quad$ Artisans value freedom and spontaneity. They want to be without constraint, at liberty to act on their impulses, play and create.

- Guardians value belonging to a group or community. They maintain stability through responsible, conservative, traditional behavior.

- Idealists value personal growth, authenticity, and integrity. They yearn to develop themselves fully as individuals and to facilitate growth in others.

- $\quad$ Rationals value competence and intelligence. They strive to learn, know, predict, and control the resources in their environment.

It has been shown through research that project managers and leaders will most likely fall into the category of either Rational or Guardian. A Rational tends to be pragmatic and organized. "Their organizational and coordinating skills tends to be highly developed, which means that they are likely to be good at systematizing, ordering priorities, generalizing, summarizing, and at demonstrating their ideas" (Prometheus Nemesis, 1998).

Guardians tend to be very concrete in their communication and reliable when it comes to completing tasks. They also are very cooperative with implementing goals and are often good at supervision and protecting. The Supervisor Guardian is the type of that most fits the personality of the project manger. Supervisor Guardians "go by experience, not speculation and experimentation, and certainly not fantasy. They keep their feet firmly on the ground and make sure that those under their supervision do the same" (Prometheus Nemesis, 1998).

The Fundamental Interpersonal Relations Orientation-Behavior (FIRO-B) instrument can also be used to assess one's personality and behavior. The FIRO-B "measures the extent to which people attempt to satisfy three basic social needs: Inclusion, Control, and Affection" (Schnell, 1998). The FIRO-B measures how often an individual initiates each type of behavior as well as how often an individual wants others to initiate these behaviors towards them. The FIRO-B assessment helps to describe the compatibility of individuals towards the teams they work with as well as team atmosphere or culture. The project manager will have a high number when describing the initiation of each type of behavior.

The three personality assessments described above are good tools to examine an individual's personality type and compare it to that of the typical project manager career. Each assessment can be used separately or they can be used in conjunction to get the best results. Using these evaluations, we can examine a person based on the skills required to be a good project manager, and decide whether to put them in that role, whether they would need further training to be successful in the project manager role, or whether they would be best placed in a different career altogether.

\section{Knowledge vs. Behavior}

"Is it better to hone natural ability occurring in some people (personality styles) rather than teaching the results achieved even when following techniques" (Levine, 2003)? If you had to choose an IT project manager, 
which would you choose: one that has PM skills and lacks PM personality or a project manager that has the PM personality and lacks the PM skills?

It has been proven that it is not difficult to learn new skills. Students taking classes are proving that everyday. "After all, what is so difficult in the PM process? To develop a project charter - defining objectives and scope, considering strategies to achieve the objectives, setting the ground rules - aren't these fairly natural management functions? Building schedules and budgets, managing the workforce, tracking progress, reporting and communicating - these should not be foreign to managers" (Levine, 2003). These skills can also be easily acquired by those that have no management experience at all.

If we can teach project management skills, why can't we take someone who has the skills and train them in the methods of leading people? We do some of this in terms of raising awareness of the issues associated with some aspects of leading a project team. However, this comes down to being much more than a training issue. "It is not knowledge that we are trying to add to, but personalities that we are trying to change" (Levine, 2003). Personalities can change, but over time. Individuals can take behavior modification training to refine their behavior to match that of a project manager. It has been shown that this training tends of have a very short half-life because people don't make the effort, once they get back into the comfortable environment, to enforce what they learned and practiced during training. Now ask yourself, which choice would be a better one. It should be somewhat obvious that given the choice to add to one's knowledge and skills, or to change one's behavior, the former would be a better choice. The latter is more likely to fail.

\section{Conclusion}

This paper has explained what it takes to be a project manager and the personalities that most match that of a project manager. The paper also discussed the conflicting issue of changing behavior vs. changing knowledge. By looking at these factors, many still have differing opinions as to whether you can teach someone to be a project manager or whether that person has to have the "gift" of project management. CIO completed research that indicated that $81 \%$ of CIO's believe that leadership can be taught. There is also a large group of people that their beliefs lie on the other side of the line. We can see that there is a very fine line as to what attitude you take on; the one that claims that you can teach everything a project manager will need to know including changing their personality, or it's the one that declares that either a project manger has it or they don't, and trying to teach them the "soft skills" necessary is just a waste of time.

There are good points to both sides of the debate. However, from all of the information provided, we would have to conclude that a great project manager is born with the skills necessary to succeed. Learning the behaviors and soft skills might give someone the ability to survive as a project manager in the project management world. However, we don't think that this person would be as successful as one with the behavioral skills they were born with.

In addition, we believe that making the attempt to teach the IT project management personality in the classroom would be futile. It can be shown by Apollo 13 that when in critical situations, people revert back to what they know, what is in their gut. If a person isn't doesn't have the gut instincts and ability to operate as a project manager under stress, they will not survive in the field. Understanding this concept, we believe that attempting to teach this in the classroom would result in failure.

If we were asked to choose my ideal project manager, we would want someone who not only had the technical skills of project management, but we would also prefer someone who had the ability to lead people and teams. We would also desire someone with the ability to communicate effectively with different types of people and inspire them to work to their utmost potential. We would want the project manger to rate as an ENTJ on the Myers Briggs Type Indicator or a Supervisor Guardian on the Temperament Sorter. Those two types are indicated to be the ideal for project management careers. This would ensure the fact that when in important decision making situations, they will rely on what they know and make a sage decision. In addition, we would attempt to determine whether the 
person has the ability to make decisions, as well as influence others to work to their optimum potential. The ability to influence and motivate others is ideal for a project's completion within its constraints.

If we were asked to choose, we would opt for someone who fits the project manager mold with all the previous qualifications. A project manager with the technical, behavioral, and instinctive skills it takes to complete projects within their constraints would be my choice no matter how many times I had to face that choice. Ultimately, we think that it is necessary for project based organizations to decipher and employ project managers that will have the ability to succeed in managing their projects and utilize their talents to optimize organizational gain and profit.

\section{References}

1. AdvisorTeam. (2003). What is the temperament sorter. Retrieved October 29, 2003, from http://www.advisorteam.com/temperament_sorter/about/.

2. Artner, B. (2001). Looking for leaders in all the wrong places. Retrieved October 22, 2003, from http://techrepublic.com.com/5102-6314-1033951.html.

3. BSM Consulting. (2000). Common careers for personality types. Retrieved October 29, 2003, from http://www.personalitypage.com/careers.html.

4. $\quad$ Canterucci, J. (2003). Leaders are made, not born. Columbus Business First: September 29. Retrieved November 30, 2003, from http://www.bizjournals.com/columbus/stories/2003/09/29/smallb2.html.

5. CIO Insight. (2003). The CIO Insight research study: Leadership. Retrieved November 11, 2003, from http://www.cioinsight.com/print article/0,3668,a=108886,00.asp.

6. Kharbanda, O, P. (2003). Project managers: Generalists not specialists. Retrieved October 25, 2003, from http://www.gantthead.com/article/1,1380,164104,00.html.

7. Levine, H, A. (2003). Choosing project managers knowledge is easier to acquire than changing behavior. Retrieved October 22, 2003, from http://www.sciforma.com/resources/white_papers/choosing_project_managers.htm.

8. Melymuka, K. (2000). Born to lead projects. Computer World: March 27. Retrieved October 31, 2003, from http://www.computerworld.com/printthis/2000/0,4814,44218,00.html.

9. Prometheus Nemesis Book Company. (1998). The four temperaments. Retrieved November 11, 2003, from http://keirsey.com/matrix.html.

10. Schnell, J. (1998). The leadership report using FIRO-B and MBTI. Retrieved October 27, 2003, from http://ransdellassociates.com/sampleReports/leadershipReportUsingFIROBandMBTI.pdf

11. Schwalbe, K. (2004). Information technology project management: Third Edition. Canada: Thomson Course Technology.

12. Viawest. (2003). Keirsey temperament versus myers-briggs types. . Retrieved October 29, 2003, from http://users.viawest.net/ keirsey/difference.html.

13. Wideman, Max. "Dominant Personality Traits Suited to Running Projects Successfully". Retrieved December 2, 2003 from http://www.maxwideman.com/papers/personality/intro.htm

\section{Reading List}

1. Wideman, M. (2003). Project manager's skills. Retrieved October 29, 2003, from http://www.maxwideman.com/guests/servant/skills.htm.

2. US. Dept. of the Interior. (2000). Connecting personality types with careers and jobs. Retrieved October 29, 2003, from http://www.doi.gov/octc/typescar.html. 
Notes 